\title{
Case Report: Locally Advanced Colorectal Cancer Diagnosed by Pathology From Abdominal Wall Necrotic Tissue
}

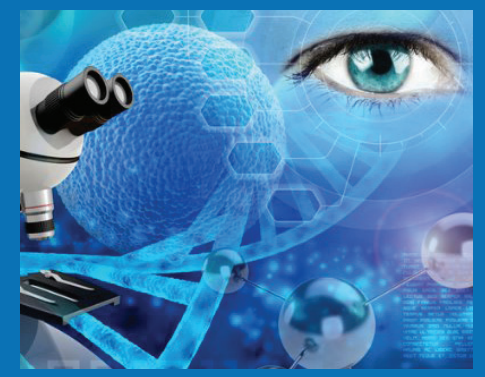

Issue Type: Volume 1 Issue 3
Author Name:

Rami Tarabay ${ }^{1}$, MD; Riwa Al Aridi ${ }^{2}$,

PharmD; Mahsa Chitsaz ${ }^{3}$, MD;

Alexander Pontikos ${ }^{4}$, MD; Ehsan

Chitsaz $^{5}$, MD

1 Department of Geriatrics, MetroHealth

Case Western Reserve University,

Cleveland, Ohio

2 Department of Pharmacology,

Lebanese International University,

Beirut, Lebanon

3 Department of Pathology, MetroHealth

Case Western Reserve University,

Cleveland, Ohio

4-5 Department of Gastroenterology,

MetroHealth Case Western Reserve

University, Cleveland, Ohio

Corresponding Author:

Rami Tarabay, MD

Citation: Rami Tarabay, MD,

Locally Advanced Colorectal Cancer

Diagnosed by Pathology From

Abdominal Wall Necrotic Tissue

Received Date: 24th May 2021

Published Date: 30th May 2021

Copyrights:

This is an open access article distributed under the Creative Commons Attribution License, which permits unrestricted use, distribution, and reproduction in any medium, provided the original work is properly cited.

\section{ABSTRACT}

Colon cancer can present with variable clinical manifestations. An unusual finding is the direct dissemination of colon adenocarcinoma through the abdominal wall and skin.

We present a rare case of complicated diverticulitis with abscess formation that demonstrates diagnosis of colonic adenocarcinoma from necrotic skin tissue upon debridement.

In the modern world of widespread use of colonoscopy screening, the initial diagnosis of colon cancer is declining. This particular case, however, illustrates the value of maintaining a high index of suspicion in patients with diver-ticulitis complicated by abscess formation.

Keywords: Locally advanced colorectal cancer, Necrotic Tissue, Pathology, Diverticulitis, Abscess

\section{Introduction}

Malignant cutaneous infiltration has been described in $0.7-9.0 \%$ of patients with visceral neoplasms (1-4) and in 5.8\% of colon cancer cases (5). While abdominal computed tomography (CT) is effective in diagnosing acute un-complicated diverticulitis, it can be difficult to differentiate it from underlying neoplasms and inflammatory condi-tions in diverticulitis complicated with perforation, fistulation and abscesses formation (6). We report a case of a patient who originally presented with acute diverticulitis and abdominal wall abscess and was subsequently diagnosed with colon cancer based on a biopsy from necrotic skin tissue debridement. Although such cases are uncommon, our findings indicate that malignant tumors should be considered during work-up of complicated diverticular diseases.

\section{Cases and Methods}

65 year old white man, former smoker, known to have sigmoid diverticulosis and prior history of diverticulitis with negative family history of malignancy, initially presented in June 2020, to the emergency of another hospital for worsening left lower quadrant abdominal pain of 1 week duration associated with diarrhea and episodes of fever.

Initial abdomen pelvis CT scan with intravenous (IV) contrast, showed sigmoid diverticulitis with microperforation and suspected early abscess formation of $2.3 \mathrm{~cm}$ in the anterior wall of the proximal sigmoid. Patient was admitted for management with "Non Per Os" status, IV antibiotic therapy and fluids with a planned diagnostic colonoscopy in 6-8 weeks after resolution of the diverticulitis. His symptoms improved with medical therapy and labs showed decrease in leukocytosis and Carcinoembryonic Antigen (CEA) $<0.5 \mathrm{ng} / \mathrm{ml}$ (Normal range: 0-2.5 ng/ml). A CT guided abscess drainage and paracentesis confirmed negative cell count but the pyogenic culture grew P. aeruginosa and E.coli.

An interval CT abdomen pelvis demonstrated proximal sigmoid colon wall thickening with persistent peridiverticu-lar abscess of $2.7 \mathrm{~cm}$ and new rectus sheath hematoma and edema of abdominal wall.

Six weeks after discharge, the patient presented again to the emergency with a picture of sepsis and cellulitis. He had acute severe generalized abdominal pain and a new 10x20 cm area of erythema underneath his umbilicus. CT abdomen pelvis revealed progressive inflammatory process in the lower abdomen and anterior extension into the abdominal wall with now large anterior abdominal wall 
abscess and connection to the sigmoid colon. An emergent CT guided drainage offered no significant clinical improvement. A repeat CT demonstrated decreased abdominal wall collection but a continued focal masslike wall thickening of the sigmoid concerning of neoplasm. A CT guided paracentesis was negative for malignancy in the ascitic fluid. However, the abscess culture grew vancomycin re-sistant enterococcus (VRE) and the histologic studies of pelvic hematoma aspiration was highly suspicious for ade-nocarcinoma.

Another CT, confirmed extensive mass involving the sigmoid over $11 \mathrm{~cm}$ length producing stricture and proximal colonic distension, with extension to the abdominal wall. After 19 days, the patient was instructed to follow up for ambulatory surgical evaluation.

One week after his second discharge, the patient presented to the emergency with increasing pain and erythema in midline lower anterior abdominal wall. His review of systems confirmed 20 pounds weight loss over the last 3 months after the onset of his symptoms with no fever or blood in stools. His vitals were stable. Physical exam showed distended abdomen, purulent discharge from draining site and 10x5 cm area of redness, swelling and indura-tion inferior to the umbilicus with no signs of peritonitis. Labs were negative for leucocytosis or acute drop in hematocrit. A CT abdomen pelvis with contrast revealed a large 7 $\mathrm{cm}$ thick walled complex cystic mass from the sig-moid colon demonstrating fistulous communication with the lower anterior abdominal wall, related to a chronic pericolonic diverticular abscess with subcutaneous emphysema, partial bowel obstruction at the level of sigmoid and moderate ascites. Patient was urgently transferred to the operating room for incision and drainage of abdominal wall abscess with debridement of necrotic tissue.

The pyogenic culture grew Enterococcus gallinarum, faecium and VRE. The pathology readings from the abdominal wall necrotic tissue confirmed invasive moderately differentiated adenocarcinoma of colon (Figure 4).

Hospital course was prolonged over 12 days during which the patient significantly improved. He was discharged with a central line to continue IV antibiotics and wound dressing at a specialized center. On a follow up phone call, the patient was recovering well. He underwent en bloc resection of the colon tumor with good prognostication.

Table 1 represents the timeline of different emergency department presentations and hospital admissions.

\section{Discussion}

Colorectal cancer (CRC) is currently the 3rd leading cause of death among men and women in the United States. In 2020, there will be an estimated 104,610 new cases of colon cancer diagnosed in the U.S. including 53,000 deaths.

Although most CRC's are diagnosed after symptoms onset (70$90 \%$ ), many CRC in the early stages are found in asymptomatic individuals. Following a diagnosis of diverticulitis, colonoscopy should be performed to rule out underlying malignancy, which can be seen in up to $1.6 \%$ of cases (7). Presentation of acute diverticulitis resulting from malignancy with abdominal wall abscess and cutaneous skin involvement is even more rare. Locally advanced colon cancer that spreads along tissue planes may result in formation of abscesses, seen only $0.3-4 \%$ of the time (8). CT scan is usually the diagnostic tool used to confirm the presence of diverticulitis in the context of the appropriate symptoms. CT scan can also access for any abscess formation or masses. This case report demonstrates the for-mation of an abdominal wall abscess over the course of a couple months with fistulous connection from the sig-moid colon to the abdominal wall with confirmation of adenocarcinoma from necrotic skin tissue debridement. Ma-lignant cutaneous infiltration has been described in $0.7-9 \%$ of patients with visceral neoplasms and in $5.8 \%$ of colon cancer cases. In two recent meta-analyses, CRC was detected by colonoscopy in $8.3-10.8 \%$ of patients with compli-cated diverticulitis, but only in $0.5-0.7 \%$ of those with uncomplicated diverticulitis (9). This emphasizes the importance of colonoscopy following an episode of uncomplicated diverticulitis as outlined by the American Society of Colon and Rectal Surgeons (ASCRS) (10). En bloc resection in cases of cutaneous involvement is the treatment of choice.

Figure 1. Computed Tomography abdomen pelvis 7/25/2020. Necrotic sigmoid colon mass invading the ab-dominal wall with abscess and fistula formation (Left: Axial view, Right: Sagittal view)

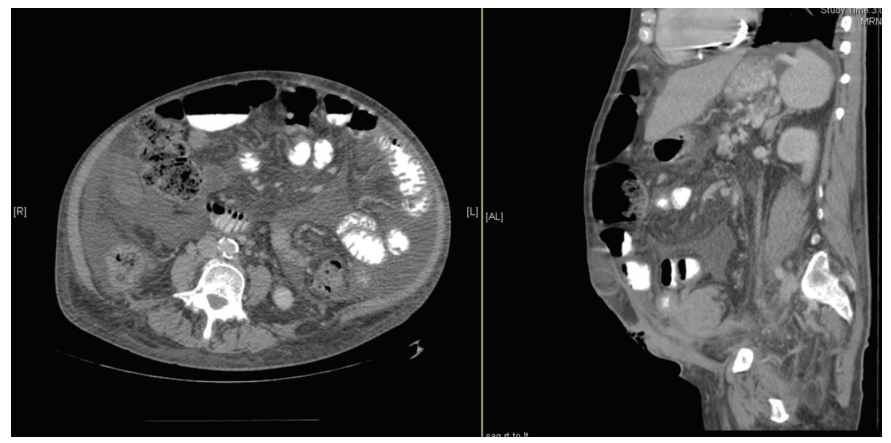

Figure 2. Computed Tomography abdomen pelvis 8/20/20. Large complex cystic mass from the sigmoid colonforming fistulous communication with the lower anterior abdominal wall (Left: Axial view, Right: Sag-ittal view)

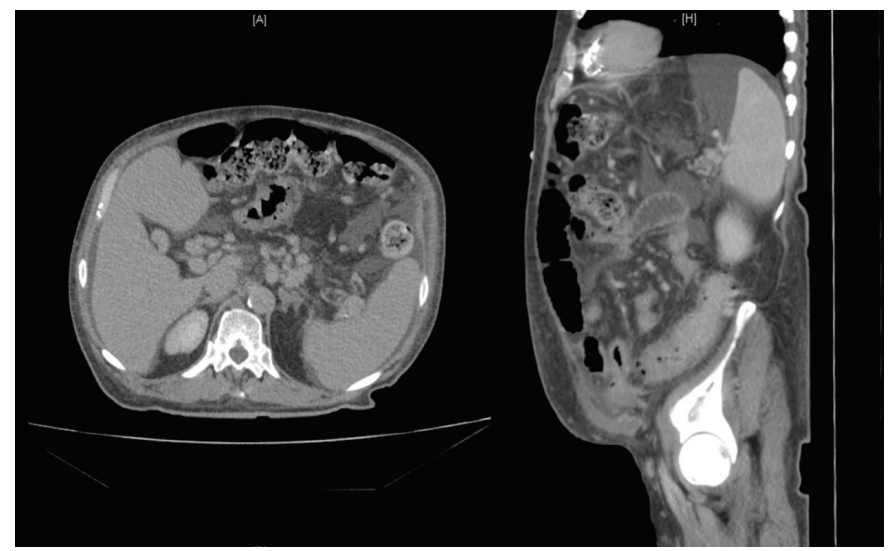

Figure 3. Abdomen post debridement of anterior wall abscess

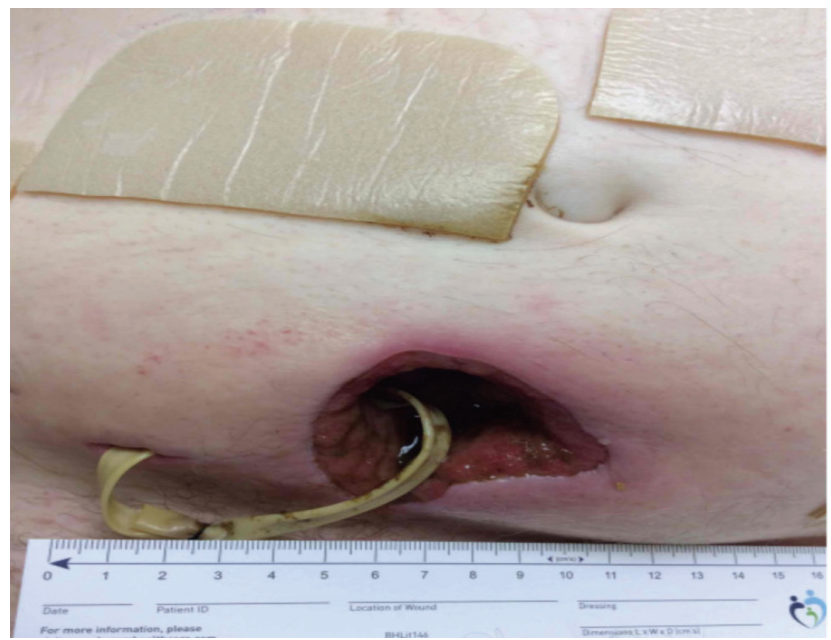


Figure 4. Pathology specimen from abdominal wall abscess debridement. Invasive moderately differentiated adenocarcinoma of colon

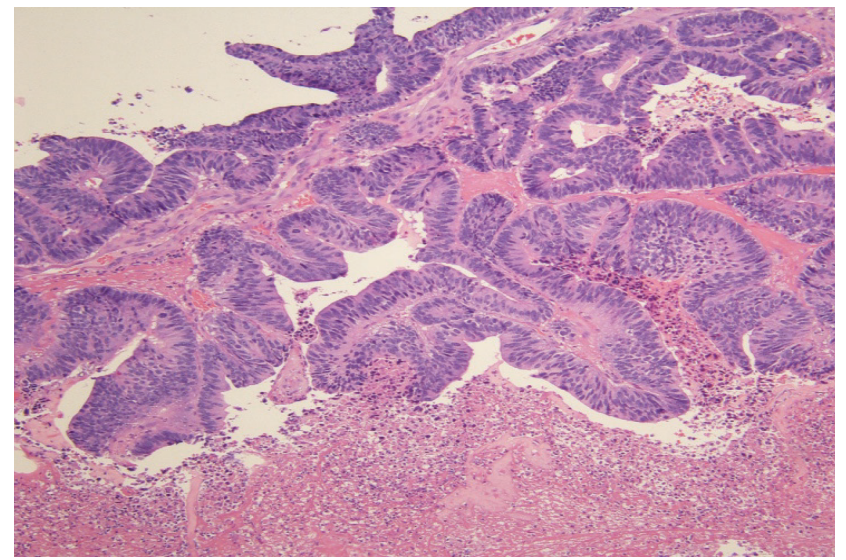

Table 1. Timeline of different emergency department presentations and hospital admissions

\begin{tabular}{|c|c|c|c|}
\hline & $\begin{array}{l}\text { First presentation and hos-pi- } \\
\text { tal admission } \\
6 / 5 / 2020 \text { till } 6 / 12 / 20 \\
\text { ( } 8 \text { days) }\end{array}$ & $\begin{array}{l}\text { Second admission } \\
7 / 25 / 20 \text { till } 8 / 12 / 20 \\
\text { (19 days) }\end{array}$ & $\begin{array}{l}\text { Third admission (Our hos-pi- } \\
\text { tal) } \\
8-20-20 \text { till 8/31/20 } \\
\text { (12 days) }\end{array}$ \\
\hline Clinical Presentation & $\begin{array}{l}\text { Left lower quadrant ab-dom- } \\
\text { inal pain of } 1 \text { week duration } \\
\text { associated with diarrhea and } \\
\text { episodes of fever }\end{array}$ & $\begin{array}{l}\text { Acute severe generalized } \\
\text { abdominal pain,cellulitis un- } \\
\text { derneath umbilicus and sepsis }\end{array}$ & $\begin{array}{l}\text {-Increasing pain and ery-the- } \\
\text { ma in midline lower anterior } \\
\text { abdominal wall } \\
-20 \text { pounds weight loss over } \\
\text { the last } 3 \text { months after the } \\
\text { onset of his symptoms } \\
\text {-Physical exam: distended } \\
\text { abdomen, purulent dis-charge } \\
\text { from draining site, worsening } \\
\text { cellulitis }\end{array}$ \\
\hline Diagnostic Assessment & $\begin{array}{l}\text {-Abdomen pelvis CT scan } \\
\text { with IV contrast: sigmoid } \\
\text { diverticulitis with microp-er- } \\
\text { foration and suspected early } \\
\text { abscess formation of } 2.3 \mathrm{~cm} \\
\text {-CT guided abscess drain-age } \\
\text { and paracentesis: nega-tive } \\
\text { cell count, pyogenic culture } \\
\text { grew P. aeruginosa and E.coli } \\
\text {-CEA }<0.5 \mathrm{ng} / \mathrm{ml}\end{array}$ & $\begin{array}{l}\text {-CT abdomen pelvis: } \\
\text { pro-gressive inflammatory } \\
\text { process in the lower ab-do- } \\
\text { men and anterior exten-sion } \\
\text { into the abdominal wall with } \\
\text { large anterior abdominal wall } \\
\text { abscess and connection to the } \\
\text { sig-moid colon } \\
\text {-CT guided paracentesis: } \\
\text { negative for malignancy in the } \\
\text { ascitic fluid } \\
\text {-Abscess culture grew VRE } \\
\text {-Histologic studies of pel-vic } \\
\text { hematoma aspiration: highly } \\
\text { suspicious for ade-nocarci- } \\
\text { noma }\end{array}$ & $\begin{array}{l}\text {-Labs: negative for leuco-cy- } \\
\text { tosis or acute drop in hema- } \\
\text { tocrit } \\
\text {-CT abdomen pelvis with con- } \\
\text { trast: large } 7 \mathrm{~cm} \text { thick walled } \\
\text { complex cystic mass from the } \\
\text { sigmoid colon with fistulous } \\
\text { com-munication with the low- } \\
\text { er anterior abdominal wall and } \\
\text { subcutaneous emphy-sema } \\
\text {-Pyogenic culture grew E. } \\
\text { gallinarum, E. faecium and } \\
\text { VRE } \\
\text {-Pathology readings from } \\
\text { the abdominal wall necrot-ic } \\
\text { tissue: invasive moder-ately } \\
\text { differentiated adeno-carcino- } \\
\text { ma of colon }\end{array}$ \\
\hline Therapeutic Interventions & Intravenous antibiotics & $\begin{array}{l}\text {-Emergent CT guided drain- } \\
\text { age and drain place-ment } \\
\text {-Intravenous antibiotics }\end{array}$ & $\begin{array}{l}\text {-Urgent transferto the op- } \\
\text { er-ating room for incision and } \\
\text { drainage of abdominal wall } \\
\text { abscess with deb-ridement of } \\
\text { necrotic tissue } \\
\text {-Intravenous antibiotics and } \\
\text { debridement site wound care } \\
\text {-En bloc resection of the colon } \\
\text { tumor }\end{array}$ \\
\hline
\end{tabular}




\section{Conclusion}

Malignant skin invasion has been identified in a limited portion of cases of colon cancer. Abdominal computed tomography can be unsatisfactory to separate acute complicated diverticulitis from existing neoplasms. The case we are discussing is a man with acute diverticulitis and abdominal wall abscess, who was eventually diagnosed with colon cancer on the basis of necrotic skin tissue debridement biopsy. While such cases are unlikely, our findings stress the significance of colonoscopy after a diverticulitis episode to screen out colon cancer.

\section{References}

1. Lookingbill DP, Spangler N, Sexton FM. Skin involvement as the presenting sign of internal carcinoma: A retrospective study of 7316 cancer patients. J Am Acad Dermatol. 1990;22(1):1926. doi:10.1016/0190-9622(90)70002-Y

2. Abrams HL, Spiro R, Goldstein N. Metastases in carcinoma. Analysis of 1000 autopsied cases. Cancer. 1950;3(1):74-85. doi:10.1002/1097-0142(1950)3:1<74::AIDCNCR2820030111>3.0.CO;2-7

3. Mcwhorter Je, Cloud Aw. Malignant Tumors And Their Metastases. Ann Surg. 1930;92(3):434-443. doi:10.1097/00000658-193009000-00014

4. Reingold IM. Cutaneous metastases from internal carcinoma. Cancer. 1966;19(2):162-168. doi:10.1002/10970142(196602)19:2<162::AID-CNCR2820190204>3.0.CO;2-A

5. Marcoval J, Moreno A, Peyrí J. Cutaneous infiltration by cancer. J Am Acad Dermatol. 2007;57(4):577-580. doi:10.1016/j. jaad.2007.01.034

6. Ben Yaacoub I, Boulay-Coletta I, Jullès MC, Zins M. CT findings of misleading features of colonic diver-ticulitis. Insights Imaging. 2011;2(1):69-84. doi:10.1007/s13244-010-0051-6

7. Meyer J, Buchs NC, Ris F. Risk of colorectal cancer in patients with diverticular Disease. World J Clin Oncol. 2018;9(6):119122. doi:10.5306/wjco.v9.i6.119

8. Attar L, Trabulsi N, Maghrabi AA, Nassif M. Adenocarcinoma of the Colon Disguised as Abdominal Wall Abscess: Case Report and Review of the Literature. Case Rep Surg. 2018;2018:1-6. doi:10.1155/2018/1974627

9. Rottier SJ, van Dijk ST, van Geloven AAW, et al. Metaanalysis of the role of colonoscopy after an epi-sode of leftsided acute diverticulitis. Br J Surg. 2019;106(8):988-997. doi:10.1002/bjs.11191

10. Hall J, Hardiman K, Lee S, et al. The American Society of Colon and Rectal Surgeons Clinical Practice Guidelines for the Treatment of Left-Sided Colonic Diverticulitis. Dis Colon Rectum. 2020:728-747. doi:10.1097/DCR.0000000000001679 